\title{
Identification of Potential Eco-tourism Site Suitability Using AHP and GIS in Dinsho District of Bale Zone, Southeastern Ethiopia
}

\author{
Kefa Feye Garedew \\ Madda Walabu University, College of Natural and Computational Science, Department of Environmental \\ Science, P.O. Box 247, Bale-Robe, Ethiopia
}

\begin{abstract}
Ecotourism is one of the fastest growing sectors in the tourism industry at present. Ecotourism has attracted increasing attention in recent years, not only as an alternative to mass tourism, means of economic development and environmental conservation. The present study is identifying the potential ecotourism sites in Dinsho district of Bale Zone, Southeastern Ethiopia using Geographic information system (GIS) and Analytic Hierarchy Process (AHP). This study was assessed the potential suitable areas for ecotourism based on Landscape (land use land cover), Topography (elevation, slope, aspect) and Climate Characteristics (rainfall). These factors were selected based to the literature reviews and the data availability. First, a resource inventory and a list of ecotourism criteria and factors were developed using the AHP method on ArcGIS 10.5. At the next stage GIS techniques were used to measure the ranking of different sites according to the set factors and identify those with the high, moderate, less and not suitable. Later, the ecotourism potential suitability map for ecotourism was created, based on the linear combination of the criteria and factors with their respective weights. The degree of suitability of each factor was classified as highly suitable, moderately suitable, less suitable and not suitable for ecotourism. The result of the study revealed that highly suitable for ecotourism potential area accounts for $24.43 \%$ (15873.6 ha), moderately suitable accounts $15.48 \%$ (10062.7ha), less potential areas $52.79 \%$ (34298.4 ha) and 7.30\% (4739.7ha) not suitable in the study area. Therefore, this study shows that the district has high potential of ecotourism which can contribute to the livelihood of the community through sustainable natural resource management. GIS and AHP are essential and effective for ecotourism site suitability selection.
\end{abstract}

Keywords: Ecotourism, Suitability, Analytic Hierarchy Process, GIS, Factors

DOI: $10.7176 / \mathrm{JTHS} / 52-02$

Publication date: December $31^{\text {st }} 2020$

\section{INTRODUCTION}

Tourism is one of the leading and the fastest growing industries in the world [1]. It is among the main economic sectors in promoting communities development through income generation and employment opportunities. Currently, with advancement in technology and globalization, tourism demonstrates a rapid growth. Tourism also plays a significant role to the economic development of many developing countries [2]. The tourism industry of Ethiopia has a great developmental future, and it is in continuous growth in recent years [3, 1].

Ethiopia possesses unique and highly valuable ecotourism resources. The combination of historical, cultural and natural ecotourism attractions has an indispensable role for its future growth $[4,1]$. The country has stunning landscapes and biodiversity, diverse culture and tradition, and ancient historical places aging. Ecotourism has a significant role to address conservation problems and generate alternative income sources for local communities [5]. It can also contribute for socio-cultural development and sustainable use of the environmental sources [6]. However, ecotourism in Ethiopia is still in its infancy and the country has not benefited the most output from its resources [7]. Similarly, ecotourism development and significance in social, environmental and economic aspect is low compared to the neighboring countries [8]. The underdevelopment of ecotourism is because of insufficient infrastructure and service provision. Absence of adequate study on ecotourism potentials and the less dissemination in the ecotourism notion and approaches hinder the effective and sustainable development of the ecotourism in Ethiopia [9,10]

The Dinsho district is one of the most important biodiversity and ecotourism sites in South east Ethiopia. The district is by magnificent Afromontane ecosystem, forest ecosystem, grassland ecosystem, water body ecosystem and spectacular landscapes, large number of endemic flora and fauna, intact cultural resources, and holding various migrant bird species. Ecotourism is also characterized by underdeveloped state in Dinsho District, which possess immense ecotourism potentials, but are also places where ecosystem degradation and biodiversity threats are intense $[11,1]$. Despite the recent growth in the number of tourists visiting the districts, the overall ecotourism is not well developed compared to resources, and so does the rate of tourist flow in the in the district. Ways to improve local governance, promoting conservation and ensuring local benefits are yet to be developed [5, 1].

To make the natural resources more valuable to local community and to preserve the environment in a good manner, ecotourism which integrates conservation of natural areas and improves the livelihood of communities should be launched[12,5]. The identification of potential ecotourism area is not measured in terms of the landscape (land use land cover) only, but many factors should be considered such as topography (elevation, slope and aspect), 
climate characteristic (rainfall and temperature). This potential ecotourism site suitability identification can be overcome by using the Analytical Hierarchy Process technique with the help of Geographic Information System. Therefore, this study was tried to identify the criteria, factors and potential ecotourism site suitability using AHP and GIS in Dinsho District of Bale Zone, Southeastern Ethiopia.

\section{MATERIALS AND METHODOLOGY}

\subsection{Description of the Study Area}

The study area is located in oromia national regional state, Bale Zone in the Dinsho District (Figure1).

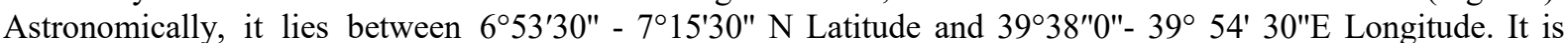
bounded by Sinana district in the East, West Arsi zone in the west, Goba district in the south and Agarfa district in the north. ). Dinsho district is one of the administrative territory of Bale zones with an area of $649.7446 \mathrm{~km}^{2}$ $(64,974.46 \mathrm{ha})$, which ranked the district the smallest district among the zonal district. The district has a distance of $30 \mathrm{~km}$ and $400 \mathrm{~km}$ from zonal Robe and country capital city Addis Ababa respectively. It has mean annual temperature of $12.5^{\circ} \mathrm{c}$ and a maximum annual temperature of $15^{\circ} \mathrm{c}$ with average rainfall $1200 \mathrm{~mm}$ per annum. Also, It has a bimodal rainfall season for the area, Belg usually extends mid-March to early August and Meher which extends early August to the end of December. The major soil types in the district are chromic luvisols, Eutric Nitosols, Eutric combisols, and Pellic Vertisols [13]

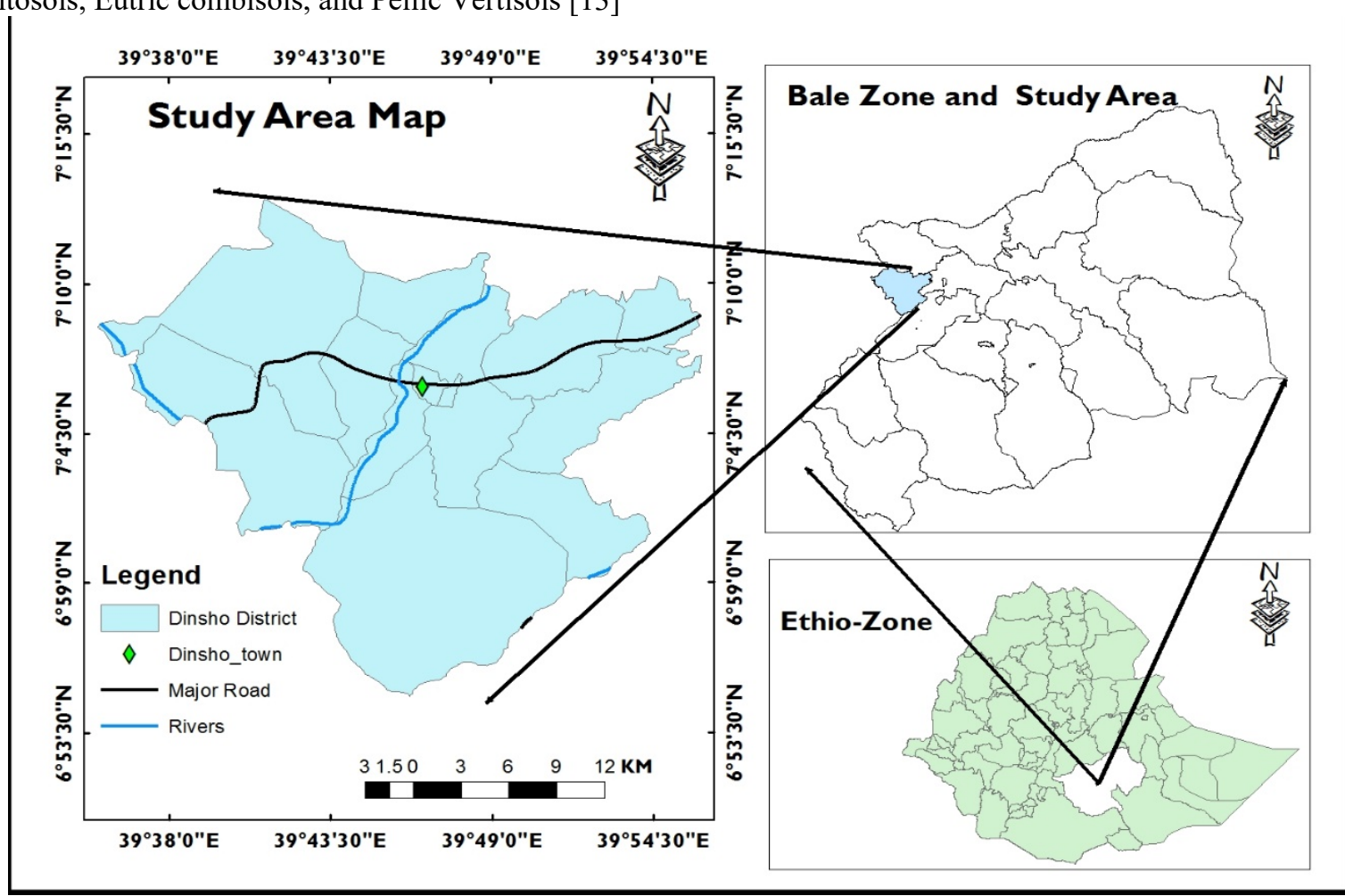

Figure 1. Map of the Study area (Ethio-GIS, 2015)

\subsection{Methodology}

\subsubsection{Sources and Types of Data}

To meet the objectives of this research, different kinds of data will be collected from both primary and secondary data sources. Data from primary sources will be satellite imagery. Secondary data such as unpublished official documents and reports was gathered from BMNP, Bale Zone and Dinsho District Environment, Forest and climate Change Authority, Culture and Tourism office.

\subsubsection{Satellite Image and GIS Data Collection}

A Landsat image of the year 2018 was used to analyze Land use Land cover class of the study area. The image data was collected from U.S. Geological Survey Center for Earth Resources Observation and Science (USGSEROS) (http://geography.usgs.gov) Operational Land Imager/Thermal Infrared Sensor (OLI/TIRS). The image used in this study was $30 \mathrm{~m}$ x $30 \mathrm{~m}$ spatial resolution. Detailed characteristics of the sources of data used for the study are shown in below table. 
Table 1 List of Data source

I. Satellite Image Data

\begin{tabular}{|c|c|c|c|c|c|c|}
\hline & Path & Row & Spatial Resolution & Source & Application & \\
\hline Landsat 8 & 167 & 55 & $30 \times 30$ meter & USGS Websites & LULC & \\
\hline SRTM & & & $30 X 30$ meter & SRTM & $\begin{array}{l}\text { Elevation, } \\
\text { and Aspect }\end{array}$ & Slope \\
\hline \multicolumn{7}{|c|}{ II. GIS Data } \\
\hline $\begin{array}{lr}\checkmark & \mathrm{T} \\
\text { study area }\end{array}$ & \multicolumn{4}{|c|}{$\begin{array}{l}\text { The Ethio- GIS data was used to generate District and kebele boundary of the } \\
\text { ea }\end{array}$} & $\begin{array}{l}\text { Dinsho } \\
\text { Boundary }\end{array}$ & District \\
\hline \multicolumn{7}{|c|}{ III. Other Ancillary Data } \\
\hline$>\quad \mathrm{C}$ & \multicolumn{6}{|c|}{ Climatic data (Rainfall) } \\
\hline \multicolumn{7}{|c|}{ IV, Software Used } \\
\hline $\begin{array}{ll}\checkmark & \text { A } \\
\checkmark & \text { A }\end{array}$ & \multicolumn{6}{|c|}{ ArcGIS 10.5: was used for GIS analysis and mapping. } \\
\hline
\end{tabular}

\subsubsection{Developing Criteria and Factors}

To evaluate and assign suitable areas for different land uses, a set of criteria and factors must be developed [14]. Consequently, in first step, the most important criteria and factors that effect on site selection ecotourism was determined. AHP was used for this purpose for making decision. AHP is a useful technique for solving multicriteria problems. The AHP uses pair wise comparison to allocate weights to the criteria of each level, measuring their relative importance by using Saaty's (1-to-9) scale, and finally calculates global weights for elements at the bottom level. The method also calculates a consistency ratio (CR) to verify the coherence of the judgments, which must be about 0.10 or less to be accepted. Mathematical foundations of the AHP can be found in [15]. In this study criteria and sub criteria were selected according to similar studies and natural conditions of the study area.

AHP method is conducted in three stages: 1) making hierarchical structure of the factors that is the most important part of AHP, 2) Calculation of the factors weight and consistency ratio (CR) of judgments should be less than $0.1[16,17]$. The pairwise comparisons and Saaty's scale was used to assess the importance of criteria and factors. The weights of factors and consistency ratio for each factor were calculated using AHP software. The consistency ration should be less than 0.1 to be accepted for assessment.

\subsubsection{Factors Maps}

In this step, map of each factor was prepared using GIS. Factors maps form an output regarding to evaluated criteria and sub-criteria identification stage. This follows right after input of information to GIS (acquisition, reformatting, geo-referencing, compiling as well as documenting related data) saved in graphical and tabular type, manipulated and analyzed to acquire desirable information.

Generally, with the help of numerous GIS techniques, a base map of the study area is created and utilized to produce a number of factors maps. Each factor is represented on a map as a layer in GIS. Every map represents one sub criterion and can be known as a thematic layer or data layer. They signify way in what the attributes are distributed in space and how they assist in achieving the objectives. Having prepared Digital Elevation Model (DEM) map of study area; elevation, slope, aspect, land use land cover class and rainfall maps were obtained in GIS environment.

\subsubsection{Weight Assigned To factors and Generation of Suitability Map}

AHP was used to determine the weight value for each criterion. It employed pairwise technique using consistency ratio index as a basis of acceptability [18]. The output of pairwise comparison matrix and computation of consistency ratio in the study areas are stated. The land suitability map for ecotourism was created based on the method employed by several authors [19]. However, each factor was categorized and their suitability scores were presented in the standardized format, that is, four suitability classes (Not suitable, less suitable, moderate suitable and high suitable) and 1 (Not suitable) to 4 (high suitable), respectively.

The total suitability score from each factor was pulled together to create site suitability map for ecotourism. The following natural continuum framework was adopted to categorize the landscape into four suitability classes [20]:

- Not suitable class: It indicates a land relatively low naturalness that is not suitable for developing ecotourism. Mostly agricultural and settlements areas.

- Less suitable class: It is an intermediate level between the not suitable and moderate suitable classes.

- Moderate suitable class: It indicates a land of moderate naturalness that may optimize the existing ecotourism resources to properly develop mass ecotourism and that can provide opportunities for mass tourists to participate in ecotourism.

- Highly suitable class: It indicates a land of high naturalness and that is suitable for developing ecotourism, which needs to meet strict environmental regulations. 


\section{Result and Discussion}

\subsection{Result}

\subsubsection{Criteria and factors}

AHP was used to assess the priority of each factor. AHP and GIS combined together to assess site suitability for ecotourism potential in Dinsho district, Southeastern Ethiopia. In this study, to assess the potential ecotourism site suitability three criteria and five factors were used including land use land cover, elevation, slope, aspect and rainfall.

Based on the result of the factors assessment, land use land cover with a weight equal to 0.556 was the most important and Elevation, slope, Aspect and rainfall were much important respectively for potential ecotourism site suitability selection analysis. The Consistency ratio CR is 0.094 . $C R=0.094<0.10$ (Acceptable). The table 2 shows the results of the hierarchy creation, the importance of the criteria and factors.

Table 1. Suitability Criteria and factors

\begin{tabular}{|c|c|c|c|c|c|c|}
\hline \multirow[b]{2}{*}{ ن } & \multirow[b]{2}{*}{ 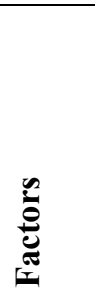 } & \multirow[b]{2}{*}{$\frac{=}{200}$} & \multicolumn{4}{|c|}{ Layer of Suitability Classification } \\
\hline & & & 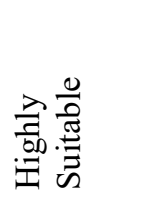 & 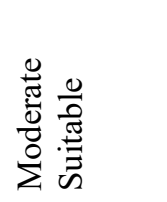 & 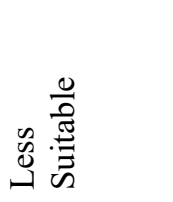 & 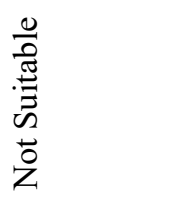 \\
\hline Landscapes & 马્ & 0.556 & $\begin{array}{c}\text { Forest, } \\
\text { water } \\
\text { body }\end{array}$ & Grasslands & Shrub land & $\begin{array}{l}\text { Agricultural } \\
\text { land, } \\
\text { settlements }\end{array}$ \\
\hline \multirow[t]{3}{*}{ Topography } & 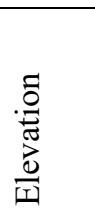 & 0.227 & $\begin{array}{l}3668- \\
4047 \mathrm{~m}\end{array}$ & $\begin{array}{c}3289- \\
3668 \mathrm{~m}\end{array}$ & $\begin{array}{c}2910- \\
3289 \mathrm{~m}\end{array}$ & $2532-2910 \mathrm{~m}$ \\
\hline & $\begin{array}{l}\frac{0}{2} \\
\frac{0}{\pi}\end{array}$ & 0.129 & $\begin{array}{c}0-15 \\
\text { degree }\end{array}$ & $\begin{array}{c}15-31 \\
\text { degree }\end{array}$ & $\begin{array}{c}31-47 \\
\text { degree }\end{array}$ & $>47$ degree \\
\hline & 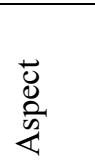 & 0.057 & $269-359$ & $179-269$ & $89-179$ & $-1-89$ \\
\hline Climate & 䒿 & 0.031 & $\begin{array}{c}1225- \\
1320 \mathrm{~mm}\end{array}$ & $\begin{array}{c}1130- \\
1225 \mathrm{~mm}\end{array}$ & $\begin{array}{c}1035- \\
1130 \mathrm{~mm}\end{array}$ & $\begin{array}{c}941- \\
1035 \mathrm{~mm}\end{array}$ \\
\hline
\end{tabular}

\subsubsection{Factors Maps}

The required factors maps derived and these maps include land use land cover, elevation, slope, aspect and rainfall. i. $\quad$ Land use Land cover Factor map and its suitability

Land use is a spatial distribution of land use in the district. Forests areas, grasslands and water body's areas have the highest value for ecotourism potential. 

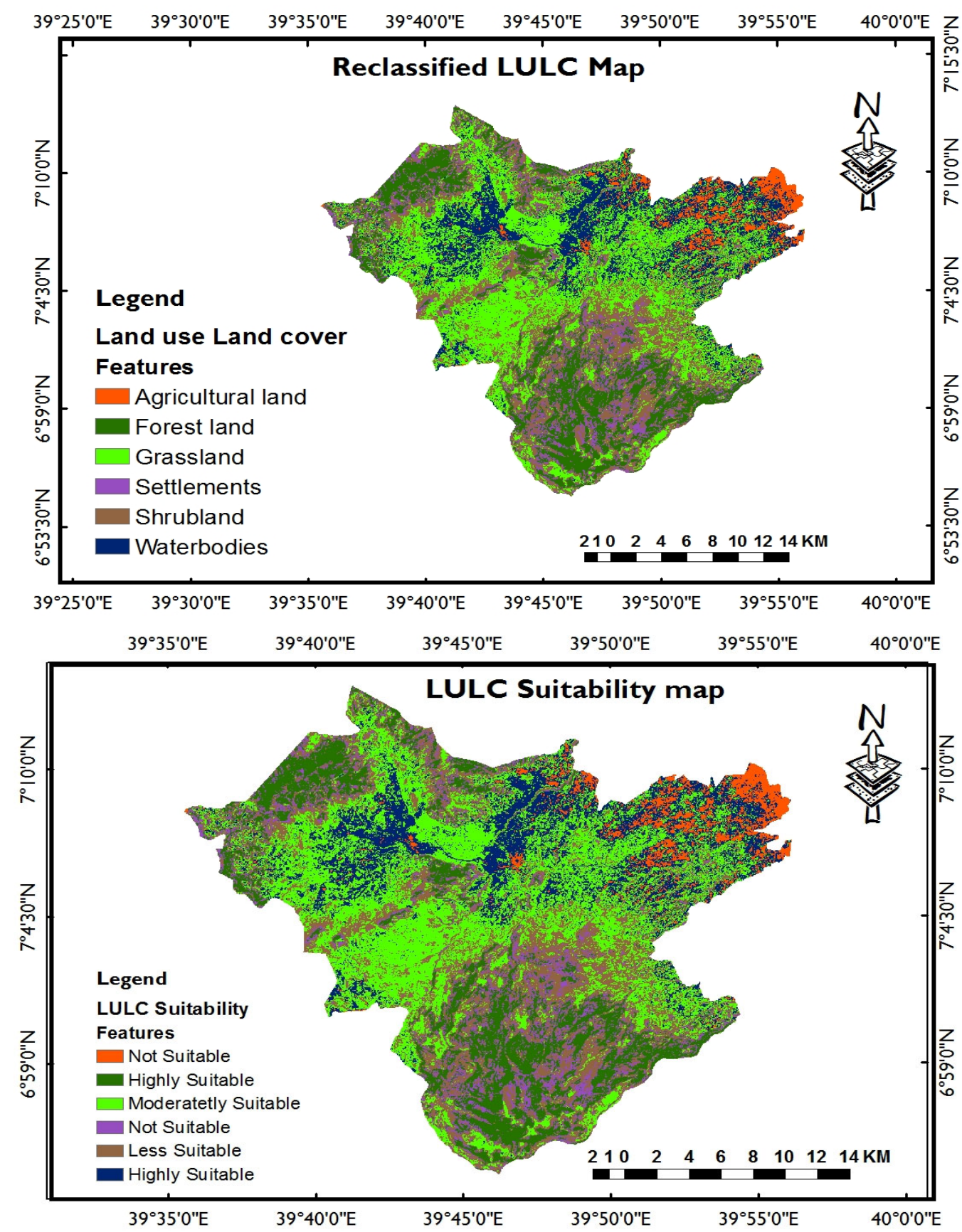

ii. Elevation Factor map and its suitability

Elevation explains hypsometrically diverse of relief. The vertical relief diverse attractiveness is reflected in its impact on the panoramic ambience, relief mosaic, as well as air quality. This elevation map is the reclassified one. 

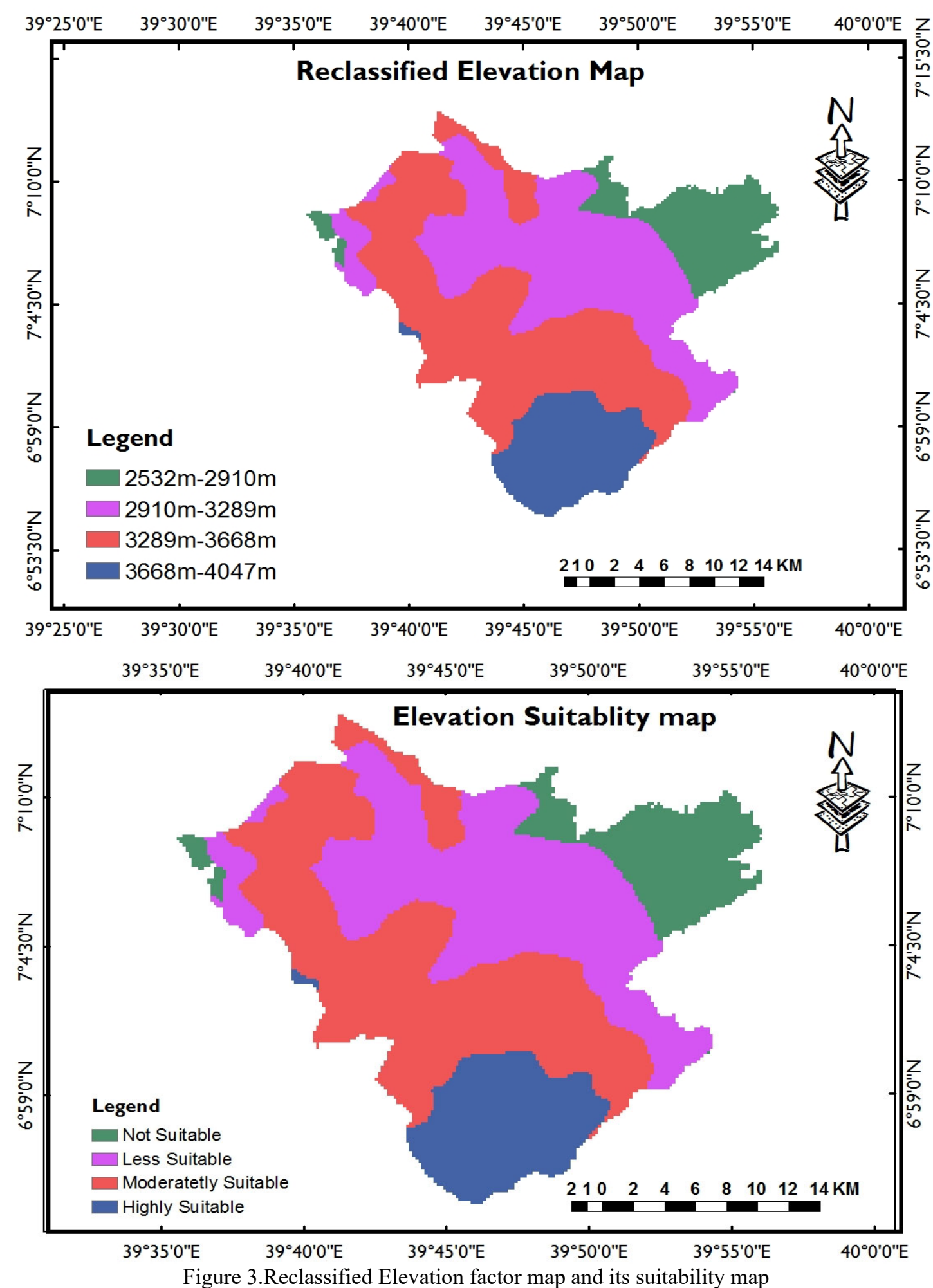

iii. Slope Factor map and its suitability

The complexity of the land slope and its distribution make a basic value of this criterion. 

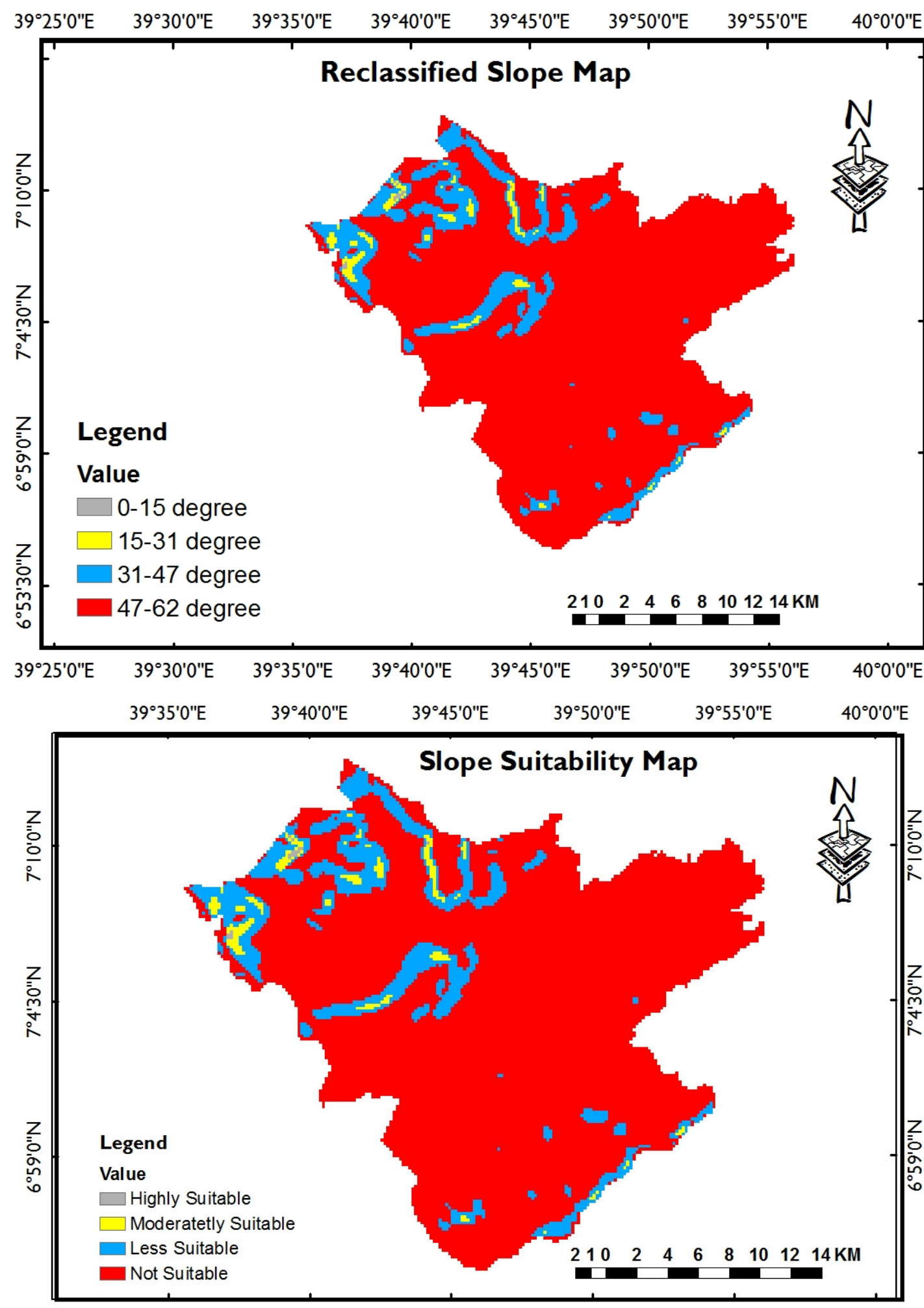
iv. Aspect Factor map and its suitability
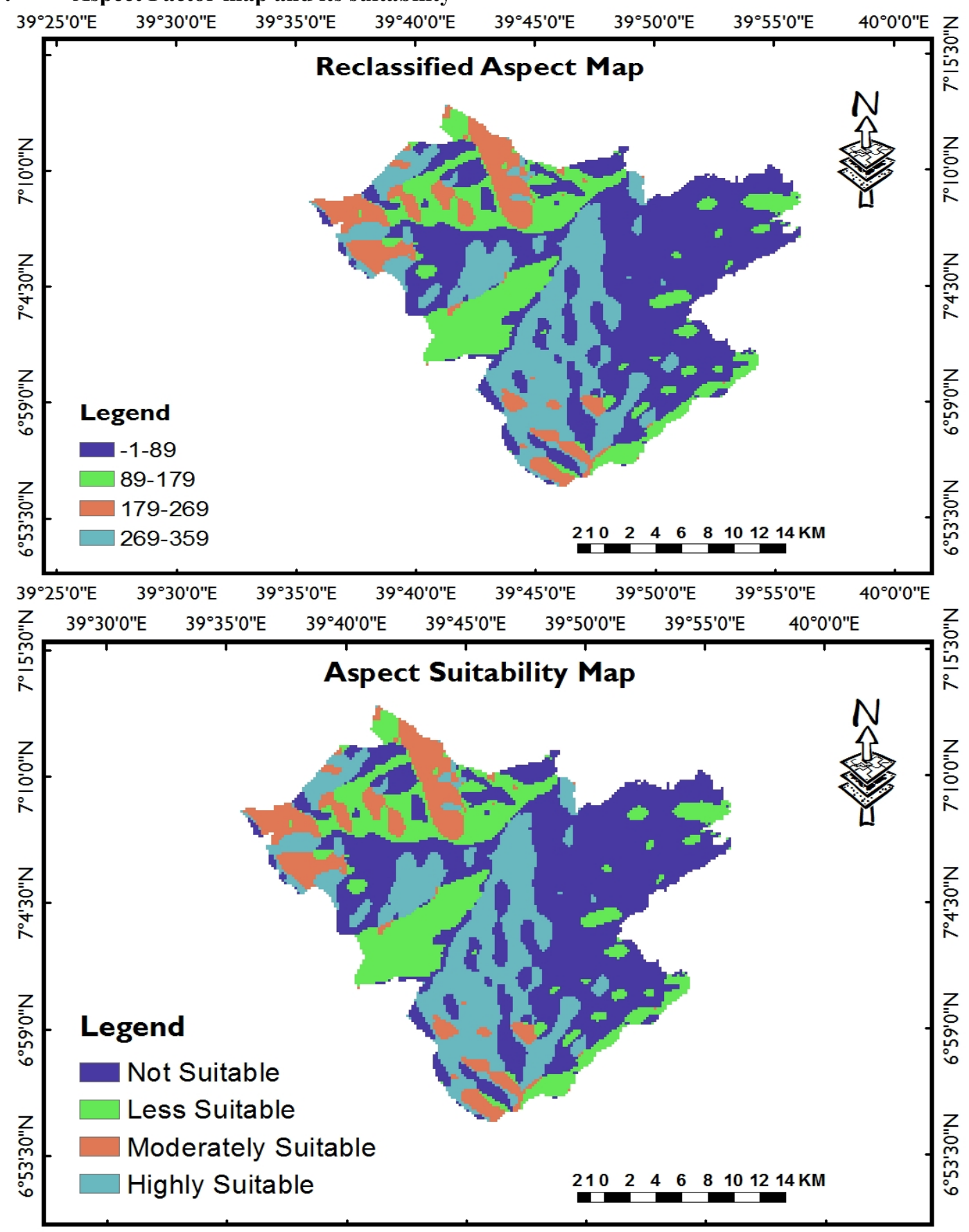

$39^{\circ} 30^{\prime} 0^{\prime \prime E} \quad 39^{\circ} 35^{\prime} 0^{\prime \prime E} \quad 39^{\circ} 40^{\prime} 0^{\prime \prime E} \quad 39^{\circ} 45^{\prime} 0^{\prime \prime E} \quad 39^{\circ} 50^{\prime} 0^{\prime \prime E} \quad 39^{\circ} 55^{\prime} 0^{\prime \prime E} \quad 40^{\circ} 0^{\prime} 0^{\prime \prime E}$

Figure 5. Reclassified Aspect factor map and its suitability map 
v. Rainfall Factor map and its suitability
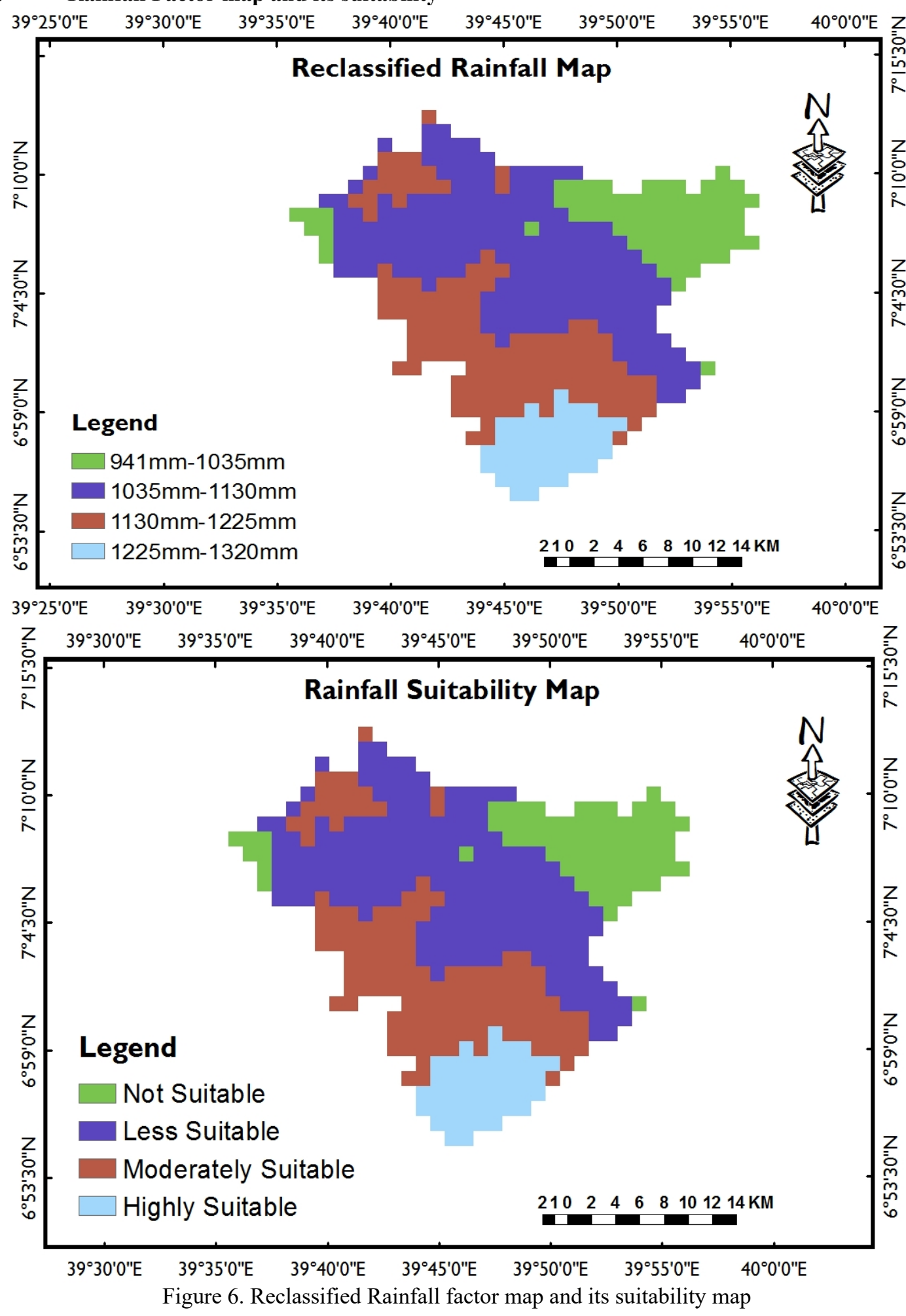

\subsection{Potential Ecotourism Site Suitability}

The major result of this study is suitable areas map for ecotourism (Fig.7) that classified in four categories. The results showed that 15873.6 ha of study area $(24.43 \%)$ was high suitable for ecotourism potential developments, 10062.7 ha $(15.48 \%)$ was moderate suitable, 34298.4 ha $(52.79 \%)$ was less suitable and 4739.7 ha $(7.30 \%)$ was not suitable for ecotourism potential development (Table 4). The most attractions ecotourism in the district are "Endemic fauna and flora , Rivers, Valley, Geology and glaciations, Local culture, Bodity Mountain , Fincanbera attraction site, Adele plateau, Konadira, and other historically crucial stones Caves, Springs and 
waterfalls[1].

Table 2. Suitability class with area coverage

\begin{tabular}{lllll}
\hline S No & Suitability Class & Area $(\mathrm{Sq} . \mathrm{km})$ & Area $(\mathrm{Ha})$ & Area $(\%)$ \\
\hline 1 & Highly Suitable & 158.736 & 15873.6 & 24.43 \\
2 & Moderate Suitable & 100.627 & 10062.7 & 15.48 \\
3 & Less Suitable & 342.984 & 34298.4 & 52.79 \\
4 & Not Suitable & 47.397 & 4739.7 & 7.30 \\
& Total & 649.7446 & 64974.46 & 100 \\
\hline
\end{tabular}

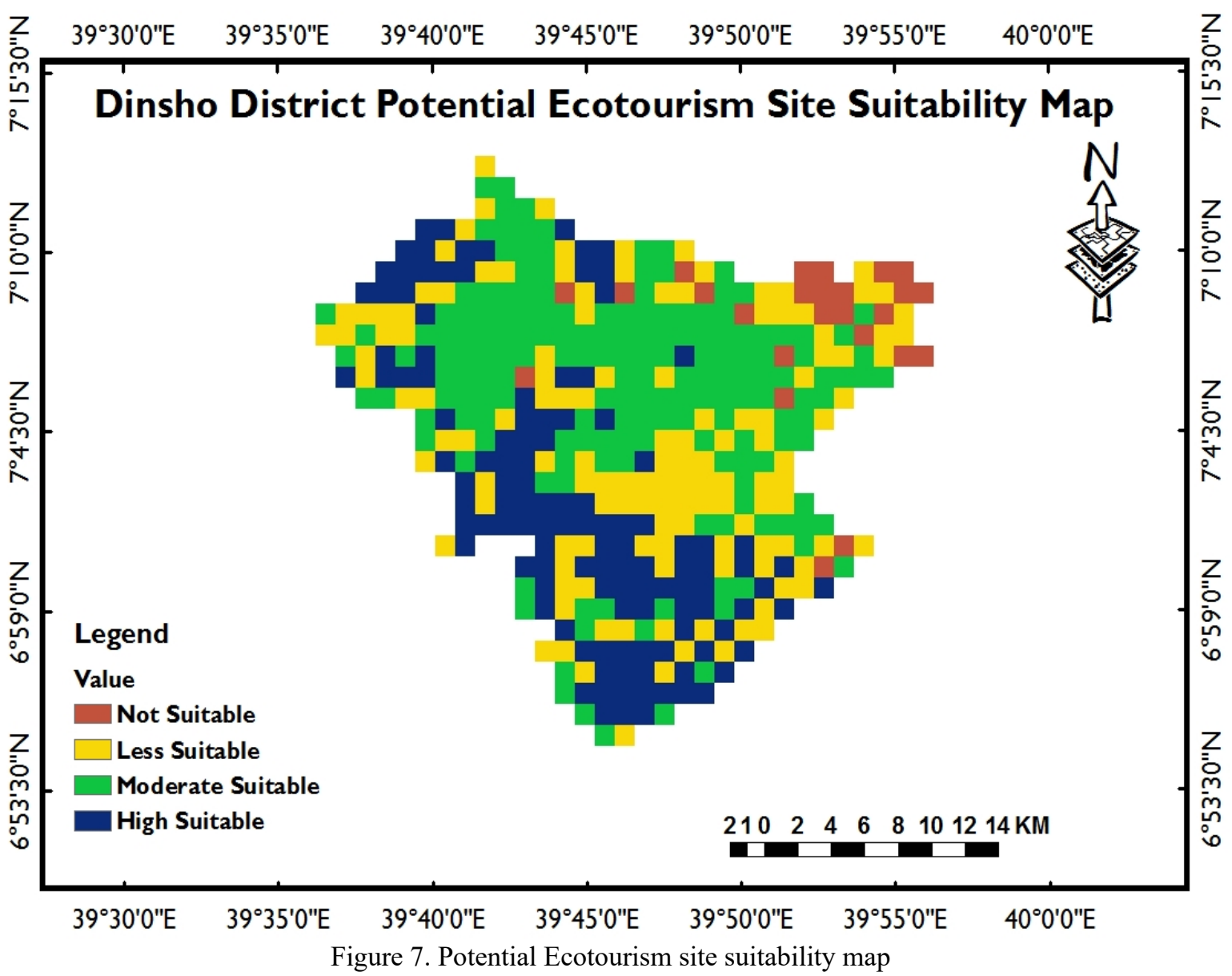

\subsection{Discussion}

The main impact of this study was the identification criteria and factors of ecotourism by applying the AHP and GIS. In this process, the research focuses to develop an integrated approach of ecotourism development by identification of ecotourism suitable sites. For ecotourism site selections, there is no uniform standard in the overall procedure of the operations; rather, it is applied based on nature, situation and available resource in a given geographic area. Therefore in the case of this study, considering the nature of the study area and the available information, time and resource, the researchers tried to include three criteria and five-factor maps. Namely: landscape (land use land cover map); topography (elevation, slope and aspect map); and climate characteristics (rainfall).The final outcome of the research is based on the level of potential for ecotourism. Therefore, an important factor has a greater impact on the outcome than other factors. Hence, the weight LULC map is $0.556 \%$ and the remaining elevation map, slope map; aspect map and rainfall map is $0.227 \%, 0.129 \%, 0.057 \%$, and $0.031 \%$ respectively. This research revealed that, the calculated consistency ratio (CR) from pairwise comparison matrix is 0.094 (less than 0.1), which indicates that a reasonable level of consistency in the pairwise comparisons and weights is acceptable.

The results showed that 15873.6 ha of study area $(24.43 \%)$ was high suitable for ecotourism potential developments, 10062.7 ha (15.48\%) was moderate suitable, 34298.4 ha (52.79\%) was less suitable and 4739.7 ha $(7.30 \%)$ was not suitable for ecotourism potential development. The ecotourism resources of Dinsho district is generally characterized by the amalgamation of biological, cultural and physical attractions. Dinsho district possess immense ecotourism attractions. 


\section{Conclusions and Recommendations \\ 4.1. Conclusions}

The main contribution of this study was the identification criteria of ecotourism by applying the AHP and GIS. This study attempted to develop ecotourism suitability model that further support decision-making process in Dinsho district of Bale Zone, Southeastern Ethiopia. In order to produce potential ecotourism suitability sites, multi-criteria decision is done based on three criterion and five-factor maps. These are; landscape (LULC map), topography (elevation, slope and Aspect map), and climate characteristics (rainfall map) were used to analysis the suitability map of ecotourism. The result of the study revealed that land use land cover is the major factor in this area to optimal site selection for ecotourism and the elevation is also important factor in ecotourism site suitability. Based on the findings, highly suitable areas for ecotourism are $24.43 \%$, moderately suitable are $15.48 \%$, less suitable is $52.79 \%$ and not suitable for ecotourism is $7.30 \%$. This provides an easy way for decision makers to manage and develop ecotourism through sustainable natural resource management in the study area.

\subsection{Recommendations}

Based on the findings of the study, the following recommendations are forwarded;

* Increasing the awareness of local communities in and around attraction area towards ecotourism through formal and informal meetings with support of concerned stakeholders.

* Additional study is needed to refine the suitability; accessibility of roads, distance from settlements, the ecological sensitivity and risky areas should be identified considered as one factor in site suitability which is not included in this study due to absent of data

* Both governmental and non-governmental organizations should take initiatives in bringing ecotourism developmental projects for local communities.

\section{Conflicts of Interest}

The author did not declare any conflict of interest

\section{References}

[1] Israel Petros Menbere and Timar Petros Menbere, (2017). Opportunities and challenges for community-based ecotourism development: A case study in Dinsho and Goba Woredas, Southeast Ethiopia

[2]Torres R, Momsen JH, (2004). Challenges and potentials for linking tourism and agriculture to achieve propoortourism objectives. Prog Devel Stud, 4: 294-318.

[3] Bayou HH, Bedane AF, (2014). Factors affecting development of tourism in Oromia Rift Valley lakes area, in Ethiopia. Int J Bus Manag, 4: 6388.

[4] Meseret C, (2010). Mammalian diversity in Borena Sayint National Park, South Wollo, Ethiopia. MSc. Thesis, Addis Ababa University, Ethiopia.

[5] Lemenih M, Mesfin D, Kindu M, Abebaw D,( 2009). Benefit Sharing Mechanisms for the Bale Eco-Region Sustainable Management. Implemented by FARM-Africa/ SOS Sahel collaboration with the Oromia region Forest Enterprises Supervisory Agency, a Final Report. pp: 1-50.

[6] Aynalem S, (2016). Key stakeholders' roles and tourism development in Bale Zone, Ethiopia. World Acad J Bus Manag Admin, 1: 1-4.

[7] Eshetu AA, (2014). Ecotourism as a viable strategy for livelihood diversification and sustainable natural resource management in Ethiopia (from eco-development paradigm point of view). J Environ Sci Water Res, 3: $40-52$

[8] Dejene SW, Seyoum H, Ready RU, (2014). Ecotourism potential and its role for sustainable development and livelihood in Awash National Park, Ethiopia. Int J Sci Res, 3: 792-796

[9] Gebreigziabiher AA, (2015). An assessment of potential resources of tourism development in Ethiopia. The case of Dejen Wereda. Afr J Hist Culture, 7:100-108.

[10] Birhan M, Gebreyes G, (2015). Review on problems, prospects and economic contribution of wildlife management and ecotourism in Ethiopia. J Vet Sci Technol, 6: 1-5.

[11] Ayele AM, (2011). Ecotourism as a sustainable development option: case study from Bale Mountains National Park. MA thesis, Addis Ababa University, Addis Ababa. pp.1-124.

[12] Temesgen G, (2015). Threats of Bale Mountains National Park and solutions, Ethiopia. J Phys Sci Environ Stud, 1: 10-16.

[13] DDFEDO (Dinsho District Finanace and Economic Development Office), (2015). Biophysical and Socioeconomic profile of Dinsho District. Bale -Dinsho, Ethiopia.

[14] Belfore S (2003) the growth of integrated coastal management and the role of indicators in integrated coastal management: introduction to the special issue. 46: 225-234.

[15] Saaty TL (1996) Decision making with dependence and feedback: the analytic network process. Pittsburgh: RWS Publications. 
[16] Cimren E, Catay B, Budak E (2007) Development of a machine tool selection system using AHP, International Journal of Advanced Manufacturing Technology 35: 363-376.

[17] Dey PK, Ramcharan EK (2008) Analytic hierarchy process helps select site for limestone quarry expansion in Barbados. Journal of Environmental Management 88: 1384-1395.

[18] Saaty TL. (1980). The analytic hierarchy process, McGraw-Hill, New York.

[19] Bunruamkaew K, Murayama Y, (2011). Site Suitability Evaluation for Ecotourism Using GIS \& AHP: A Case Study of Surat Thani Province, Thailand. Procedia Social and Behavioral Sciences 21, 269-278.

[20] Wu, W., Zhang, X., Yang, Z., Qin, W., Wang, F., \& Wang, C. (2015). Ecotourism suitability and zoning from the tourist perspective: A nature reserve case study. Polish Journal of Environmental Studies, 24(6), 26832697.

[21] Demeke Asmamaw and Eskinder Gidey , (2018). Identification of Potential Eco-tourism Site Suitability Using AHP and GIS, A Case of Hugumburda Forest and its Surrounding Areas, Ethiopia.Debre Markos. On Journal of Advance in Environmental Waste Management \& Recycling. Vol 1. 